\title{
Murmur of Persistent Ductus Arteriosus in Premature Infants
}

\author{
K. A. HALLIDIE-SMITH \\ From the Department of Medicine (Clinical Cardiology), Royal Postgraduate Medical School, London
}

\begin{abstract}
Hallidie-Smith, K. A. (1972). Archives of Disease in Childhood, 47, 725. Murmur of persistent ductus arteriosus in premature infants. A longterm survey of the repeated clinical examination of premature newborn infants is reported.

There were 52 infants in whom there was well-documented clinical and phonocardiographic evidence of delayed closure of the ductus arteriosus. The ductus is believed to have closed spontaneously in 47 of them before 6 months of age and to have persisted in 5 .

Nine infants developed heart failure and all were treated medically. 8 recovered and the ductus subsequently closed spontaneously. The ninth (birthweight $1132 \mathrm{~g}$ ) died in heart failure with a widely patent ductus.

The characteristics of the various murmurs ascribed to the persistent ductus arteriosus are described and discussed. Extreme lability of the factors determining flow through the duct is suggested by the rapidly changing characteristics of the murmurs recorded.
\end{abstract}

The characteristic features of a persistent ductus arteriosus presenting in children and adults are well known and accepted as diagnostic proof without further confirmation. The characteristic continuous murmur has been reported as occurring transiently in normal full-term infants during the first few days of life (Burnard, 1958; Braudo and Rowe, 1961), and in premature infants in the first few weeks of life (Powell, 1963; Auld, 1966; Danilowicz, Rudolph, and Hoffman, 1966), and is thought to be evidence of functional patency of the ductus before its spontaneous closure. However, it is well known that a widely persistent ductus may be silent or a systolic murmur only may be recorded in young infants with persistent ductus proven by cardiac catheterization (Rudolph et al., 1958). Rowe and Lowe (1964) described three types of murmurs heard in infants with proven ducts and felt that the two 'atypical' ones were in fact diagnostically characteristic.

Delayed spontaneous closure of the ductus in a small number of premature infants has been reported (Auld, 1966; Danilowicz et al., 1966). A recent report has confirmed this and drawn attention to some of the possible determining factors (Girling and Hallidie-Smith, 1971), and to the factors which may influence this. This paper

Received 25 February 1972. reviews a 15-year experience of the clinical cardiovascular examination of premature infants, describing the cardiac murmurs which were thought to be diagnostic of a persistent ductus arteriosus, their possible haemodynamic significance, and their differential diagnosis.

\section{Material and Methods}

The material was provided by over 700 newborn infants born over the past 15 years and admitted to special care neonatal units. These infants all weighed less than $2.5 \mathrm{~kg}$ at birth and the majority were of less than 37 weeks' gestation. They were examined in an attempt to compare the clinical cardiovascular findings of premature infants with those already described in term infants (Hallidie-Smith, 1960). 50 of these infants were examined within the first 24 hours of birth, then daily until their discharge or for a maximum of 6 weeks and at subsequent follow-up visits until 1 year of age. In one year the majority of 229 premature and sick infants admitted to a neonatal special care unit were examined at least twice weekly. The other infants were examined on one or more occasions or were then specially referred by the paediatric house physician on account of a cardiac murmur. Once a cardiac murmur was heard, the infant was followed up until either it had disappeared or had been adequately explained. When possible any murmur heard clinically was documented by a phonocardiographic record. Electrocardiograms and chest $x$-rays were taken on the 


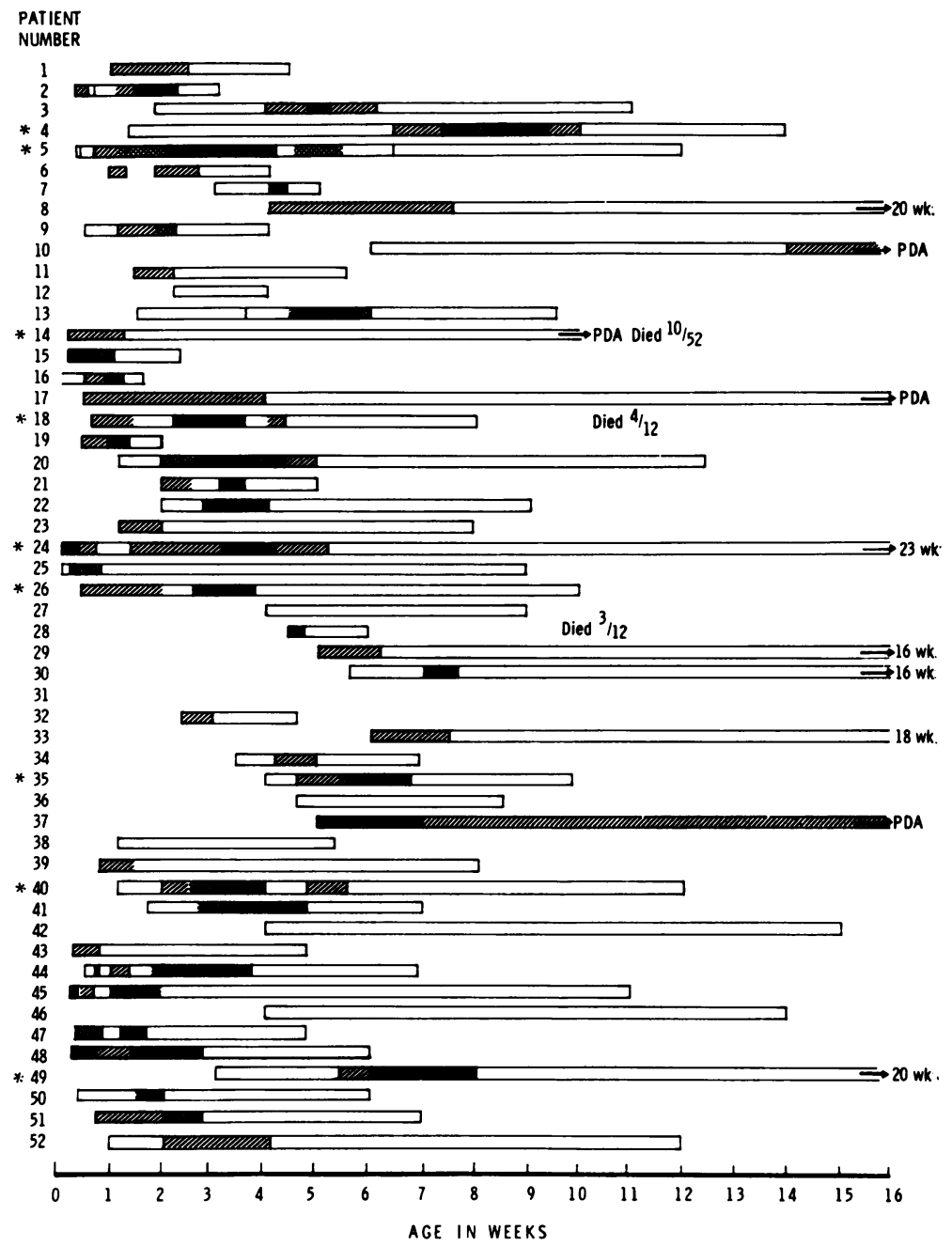

HEART MURMURS

FIG. 1.-Duration and characteristics of murmurs ascribed to a persistent ductus arteriosus in 52 premature infants.

majority of infants in whom a ductus murmur was suspected and in all infants in whom such a murmur persisted for more than a week.

\section{Results}

Transient continuous murmurs and other murmurs attributed to a ductus arteriosus were com- paratively common within the first week of life. 52 infants, examined at birth and subsequently at frequent intervals, presented with murmurs persisting for more than one week and attributed to a persistent ductus arteriosus. The auscultatory findings, amplified by phonocardiographic records in all cases, are shown in Fig. 1. 
A

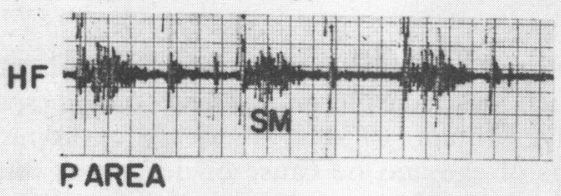

B

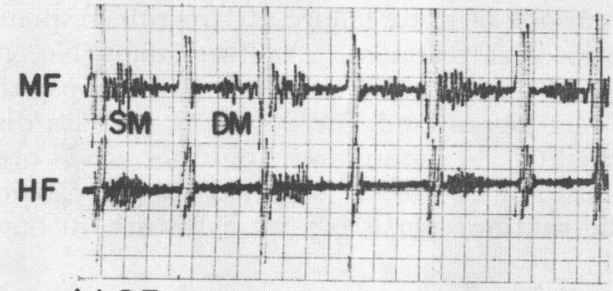

LLSE

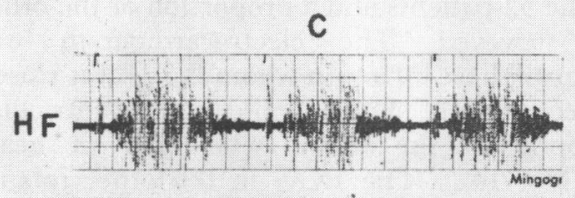

P. AREA

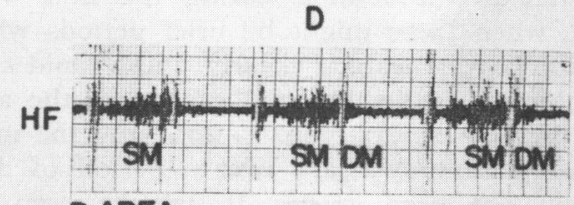

P. AREA
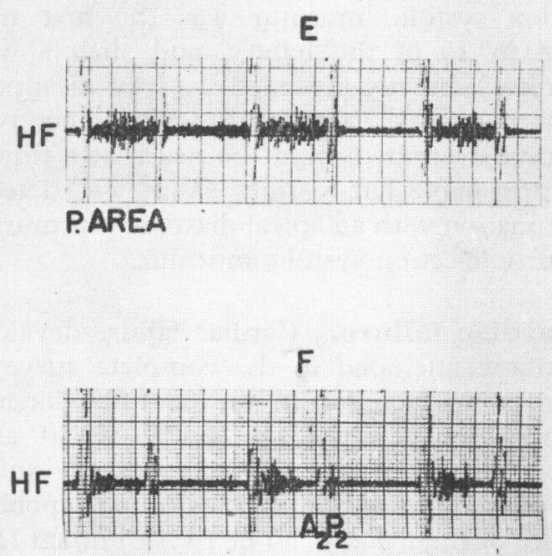

P. AREA

Fig. 2.-Typical ductus murmurs in a premature infant (No. 5). (A) Ejection systolic murmur (aged 4 days); (B) ejection systolic murmur and delayed diastolic murmur, best heard at apex (aged $4 \frac{1}{2}$ weeks); (C) continuous murmur (aged 3 weeks); (D) systolic murmur continuous into early diastole (aged 5 weeks); (E) pansystolic murmur (aged 8 days); and $(\mathrm{F})$ ejection systolic murmur (aged 9 weeks).

P. Area, pulmonary area; HF, high frequency; LLSE, lower left sternal edge; $M F$, medium frequency.

Four types of murmur were most commonly heard, characteristically maximal in the pulmonary area. First, a high pitched ejection systolic murmur, sometimes maximal lower down the left sternal edge; second, a long crescendo systolic murmur; third, a murmur continuous through systole into early diastole; and fourth, a continuous murmur. When there was evidence of an appreciable left-to-right shunt as judged by a hyperdynamic cardiac impulse and jerky arterial pulses, a low pitched apical diastolic murmur and a low pitched ejection systolic murmur, maximal at the lower left sternal edge and transmitted to the aortic area, were heard. This latter murmur was sometimes heard in the absence of other murmurs. The murmurs heard varied in their characteristics, not only from week to week or day to day (Fig.
2 A-F), but also from hour to hour (Fig. 3a, b) and sometimes even from one cardiac cycle to the

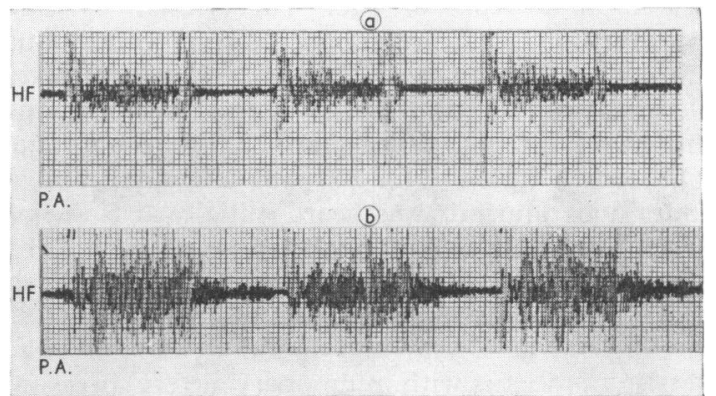

Fig. 3.-Phonocardiograms taken at an interval of 45 minutes in a 2-week-old infant (a) pansystolic murmur; (b) continuous murmur. 
next. The changing character of the murmur was particularly noticeable during the first week of life, when there might be brief periods when no murmur was heard. Clearly, these rapid changes could not be documented exactly in the analysis of these murmurs (Fig. 1) and only the murmur most commonly heard over a period of days or weeks has been given. It will be seen that a continuous murmur was the first 'established' murmur in only 2 infants, though it was documented more than transiently in 22 other infants. The ejection systolic murmur was the first murmur heard in 15 of the babies, and such a murmur invariably directly preceded the final disappearance of all murmurs. Any of the four main types of murmur described might be heard at a time when an appreciable left-to-right shunt was detected in combination with an apical diastolic murmur and/or an aortic ejection systolic murmur.

Cardiac failure. Cardiac failure developed in 12 infants included in the complete survey, 9 of whom were included in the 52 fully documented infants (Nos. 4, 5, 14, 18, 24, 26, 35, 40, and 49). The heart failure was treated medically and 11 of the infants recovered with ultimate spontaneous closure of their ducts. The twelfth infant (No. 14) weighed $1 \mathrm{~kg}$ at birth and died in heart failure at 10 weeks. The only abnormality at necropsy was a widely patent ductus arteriosus. The initial murmur was heard at 2 days and was pansystolic; a soft ejection systolic murmur was heard from the 10th day until the time of death.

Persistence of ductus arteriosus into childhood. There were 6 instances of persistent ductus in the complete survey and 4 in the series of 52 fully documented infants (Nos. 10, 14, 17, 37). Infant 14 has already been described. Infant 10 had a moderate sized duct successfully ligated at 5 years of age. An ejection systolic murmur was first heard at 6 weeks and a continuous murmur at 14 months. Patient 17 is now 5 years old and awaits ligation of her ductus; a continuous murmur was not heard until $2 \frac{1}{2}$ years of age. The fourth infant (No. 37) was a mongol and a continuous murmur was heard initially at 5 weeks. After two weeks a pansystolic murmur was heard and this persisted. At 6 months she developed heart failure which was treated medically. She was investigated at 1 year and found to have a large persistent ductus with pulmonary artery pressure at systemic level, pulmonary arteriolar resistance of 18 units, and a small bidirectional shunt at duct level. She died suddenly of pneumonia two months later and a widely patent ductus was found at necropsy but no other intracardiac defect.

Unrelated deaths. Two infants died after their duct was considered to have closed spontaneously. Infant 18 died suddenly at home at 4 months of age and no cause of death was found at necropsy; the duct was closed. Various characteristic duct murmurs had been heard from the first week until the eighth week and she had had a brief episode of heart failure at 1 month, responding to medical treatment. Another infant (No. 28) died of pneumonia at 3 months. At necropsy the duct was closed and there was no intracardiac abnormality. A continuous murmur had been first heard at 4 weeks, followed by an ejection systolic murmur persisting for a further 10 days.

Electrocardiograms and chest x-rays. Electrocardiograms and chest $x$-rays were carried out on the 52 patients and a proportion of the other infants surveyed. The electrocardiogram was normal in all those infants in whom the ductus closed spontaneously. It showed mild right ventricular hypertrophy in the infant who died in heart failure (No. 14). The ECG in the other infants with persistent ductus arteriosus was normal in the first four months of life. Slight to moderate cardiomegaly, with increased pulmonary vascularity, was shown only in infants under 4 months of age who were in heart failure at the time.

Duration of ductus murmur. The total duration of the various transient murmurs attributed to a persistent ductus arteriosus heard in the 52 infants (Fig. 1) is shown to have varied between 10 days and 23 weeks. As previously mentioned, there were a number of infants, not included in the documented series, in whom transient murmurs attributed to the ductus were heard in the first week of life. In the majority of infants a ductus murmur was first heard before the third week, but could be heard for the first time as late as the sixth week. In the majority of patients no murmurs were heard after the eighth week, but in 7 infants they persisted after the twelfth week for a maximum of 21 weeks, though spontaneous closure probably eventually occurred.

\section{Discussion}

The factors determining flow through a patent ductus and the exact aetiology of the murmurs are incompletely understood. The typical murmur heard has been ascribed to the development of 
turbulence in rapidly flowing blood (Rushmer, 1970). Clearly the major determining factors are dependent on the length and internal diameter of the ductus and the differential pressures and resistances in the systemic and pulmonary circuits. Thus, in the newborn infant with a widely patent ductus and high pulmonary vascular resistance, only small shunts through the ductus can be measured (Eldridge and Hultgren, 1955; Moss, Emmanouilides, and Duffie, 1963), and either no murmur or a very soft bruit is detected. If the ductus remains widely open and the pulmonary vascular resistance falls, then the left-to-right shunt will increase and the greater flow through the ductus may change the pressure relation across it so that there is an appreciable systolic gradient and small or negligible diastolic gradient. If so, a systolic murmur only is heard, which may last throughout systole and continue into early diastole (Rudolph et al., 1958; Leatham, 1970). A continuous murmur is heard when the diastolic gradient is increased, either by partial constriction of a ductus, a further fall in pulmonary vascular resistance, or a rise in the systemic pressure of the growing infant (Crevasse and Logue, 1959), or a combination of these factors. With increasing constriction of the ductus, the flow through it may produce only a short ejection systolic murmur (Gross, 1952). A loud ejection systolic murmur, transmitted to the aortic area, has also been described and ascribed to increased left ventricular stroke volume (Leatham, 1970). This murmur was noted in some of the infants in our series, all of whom had signs of an appreciable left-to-right shunt at the time.

The various types of murmur heard in infants with persistent ductus have been well documented and correlated with haemodynamic data (Rowe and Lowe, 1964; Rudolph et al., 1958), but the characteristics of ductus murmurs in premature infants in whom spontaneous closure subsequently occurred have not been previously described. The various characteristic murmurs of a persistent ductus reported previously were recorded in these premature infants. During the initial silent period before murmurs were heard it is assumed that the ductus was widely open and the pulmonary vascular resistance high. A soft ejection systolic murmur at the pulmonary area invariably immediately preceded the final disappearance of all murmurs. The changing character of the ductus murmur has been noted in premature infants (Powell, 1963; Auld, 1966), but the very rapid changes in the murmur noted in many of our infants (Fig. 3a, b) have not been previously described. This observa- tion in this group of premature infants, in most of whom spontaneous closure of the duct finally occurred, suggests the extreme lability of the pulmonary vascular bed, systemic arterial pressure, and contractility of the duct itself.

The differential diagnosis of the ductus murmur heard in the infants was from a functional murmur or pulmonary stenosis where the murmur was of ejection type, and from ventricular septal defect when the murmur was pansystolic. Previous work has shown that a functional systolic murmur indistinguishable from that heard in normal children may be heard in $80 \%$ of normal term infants by the end of the first week of life (HallidieSmith, 1960). However, such murmurs are uncommon in premature infants less than 1 month of age (Hallidie-Smith, unpublished) and characteristically are low pitched, heard best at the lower left sternal edge, and persistent. The murmur of pulmonary stenosis is usually easily audible at birth and also persists. The pansystolic murmur of a ventricular septal defect may be almost identical to that heard in a persistent ductus and the site of maximum intensity may prove impossible to localize. In this event the administration of a pressor drug may temporarily increase the diastolic gradient and allow a continuous murmur to be heard (Crevasse and Logue, 1959).

Delayed closure of the ductus in premature infants has been previously reported (Auld, 1966; Powell, 1963; Danilowicz et al., 1966; Girling and Hallidie-Smith, 1971). The present series emphasizes that delayed closure of the ductus in premature infants is not unusual and may occur spontaneously up to 6 months of age. Spontaneous closure of the ductus after heart failure has also been previously reported (Auld, 1966; Powell, 1963; Danilowicz et al., 1966). We believe that spontaneous closure occurred in 8 of the 9 infants treated medically for heart failure and there was necropsy proof in one of them. Ligation of persistent ductus arteriosus causing heart failure in infancy has been suggested (Ziegler, 1952; Rudolph et al., 1958), but the high incidence of spontaneous closure encourages a more conservative attitude, particularly in tiny premature infants.

I am indebted to Drs. J. Rubie, G. Newns, A. A. Cunningham, Professor J. P. M. Tizard, and the late Dr. J. J. Kempton for permission to study the infants under their care, and to Professor J. F. Goodwin for his helpful criticism.

\section{REFERENCES}

Auld, P. A. M. (1966). Delayed closure of the ductus arteriosus. fournal of Pediatrics, 69, 61. 
Braudo, M., and Rowe, R. D. (1961). Auscultation of the heart: early neonatal period. American fournal of Diseases of Children, $101,575$.

Burnard, E. D. (1958). A murmur from the ductus arteriosus in the newborn baby. British Medical fournal, 1, 806.

Crevasse, L. E., and Logue, R. B. (1959). Atypical patent ductus arteriosus: the use of vasopressor agent as a diagnostic aid. Circulation, 19, 332.

Danilowicz, D., Rudolph, A. M., and Hoffman, J. I. E. (1966), Delayed closure of the ductus arteriosus in premature infants. Pediatrics, 37, 74.

Eldridge, F. L., and Hultgren, H. N. (1955). The physiologic closure of the ductus arteriosus in the newborn infant. Fournal of Clinical Investigation, 34, 987.

Girling, D. J., and Hallidie-Smith, K. A. (1971). Persistent ductus arteriosus in ill and premature babies. Archives of Disease in Childhood, 46, 177.

Gross, R. E. (1952). The patent ductus arteriosus: observations on diagnosis and therapy in 525 surgically treated cases. American fournal of Medicine, 12, 472.

Hallidie-Smith, K. A. (1960). Some auscultatory and phonocardiographic findings observed in early infancy. British Medical fournal, 1, 756.
Leatham, A. (1970). Auscultation of the Heart and Phonocardiography, p. 128. Churchill, London.

Moss, A. J., Emmanouilides, G., and Duffie, E. R., Jr. (1963). Closure of the ductus arteriosus in the newborn infant. Pediatrics, 32, 25.

Powell, M. L. (1963). Patent ductus arteriosus in premature infants. Medical fournal of Australia, 2, 58.

Rowe, R. D., and Lowe, J. B. (1964). Auscultation in the diagnosis of persistent ductus arteriosus in infancy: a study of 50 patients. New Zealand Medical fournal, 63, 195.

Rudolph, A. M., Mayer, F. E., Nadas, A. S., and Gross, R. E. (1958). Patent ductus arteriosus: a clinical and hemodynamic study of 23 patients in the first year of life. Pediatrics, 22, 892.

Rushmer, R. F. (1970). Cardiovascular Haemodynamics, 3rd ed. p. 318. Saunders, Philadelphia.

Ziegler, R. F. (1952). The importance of patent ductus arteriosus in infants. American Heart fournal, 43, 553.

Correspondence to Dr. K. A. Hallidie-Smith, Royal Postgraduate Medical School, Hammersmith Hospital, Du Cane Road, London W12 0HS. 